\title{
The relaxant effect of Tamsulosin in the vascular reactivity of goat isolated renal artery
}

\author{
Aveen Muhsin Asaad \\ Medical Laboratory Technology Department \\ Koya Technical Institute \\ Erbil Polytechnic University \\ Koya, Iraq \\ aveen.muhsin@gmail.com
}

\author{
Ismail Salih Ibraheem Kakey \\ Department of Biology, \\ Faculty of Science and Health, \\ Koya University, \\ Koya Iraq \\ esmail.kakey@koyauniversity.org
}

\begin{abstract}
Volume 4 - Special Issue: 3rd International Conference on Health \& Medical Sciences: Insight into Advanced Medical Research (ICHMS 2019)

DOI:

10.24017/science.2019

.ICHMS.11

Received:

3 June 2019

Accepted:

8 July 2019

Alpha-blockers including tamsulosin, are medications that relax muscles in the urinary tract to facilitate stone passage into the bladder. This research aimed to investigate the possible action of tamsulosin $\left(1 \times 10^{-3}-10^{-8} \mathrm{M}\right)$, in the vascular reactivity of goat isolated renal artery by using the organ bath and PowerLab data acquisition system.

The results of recording and analysing showed that tamsulosin caused a concentrated-dependent relaxation of endothelium intact renal artery rings precontracted with a high level of $\mathrm{KCl}(60 \mathrm{mM})$ or phenylephrine (PE) $\left(10^{-5} \mathrm{M}\right)$, also tamsulosin exhibited potent inhibitory effects on $P E$, and less potent on $\mathrm{KCl}$-induced contractions. Renal artery rings preincubated with potassium $\left(K^{+}\right)$channels blocker glibenclamide (GLIB), 4-aminopyridine (4-AP), prostaglandin $\mathrm{I}_{2}$ (PGI) inhibitor (indomethacin) and epoxyeicosatrienoic acid (EET) inhibitor (Clotrimazole) have a significant effect in relaxation induced by tamsulosin. On the other side, subtype blockers from other $\mathrm{K}^{+}$channels (tetraethylammonium, TEA), barium chloride $\left(\mathrm{BaCl}_{2}\right)$ and inhibitor of nitric oxide (NO) synthase (LName) not exhibited any role in the relaxation effect of tamsulosin. Furthermore, the role of L-type of calcium channels (nifedipine) and tamsulosin, suggesting a $\mathrm{Ca}^{++}$ channel blocking mechanism has a relaxant effect in the urinary tract smooth muscles. Thus, from these results, it can be concluded that both potassium and calcium channels play an important role in relaxation effect of tamsulosin, which is mediated possibly through blocking of $K_{V}, K_{A T P}$, $P G I_{2}$, EET and voltage-dependent calcium channels.
\end{abstract}

Keywords: Tamsulosin, Smooth muscles relaxation, Renal artery, Channel blockers. 


\section{INTRODUCTION}

$\alpha$-blockers are drugs that cause relaxation of the smooth muscles in the urinary tract's wall and may additionally facilitate passing of the stones which formed in the ureter to the bladder, $\alpha_{1}$ AR was significantly activated in the renal artery and the blockers of the $\alpha$-adrenergic receptors, as tamsulosin, consequently they typically used to improve passing of the stones through medical expulsive therapy (MET)[1, 2]. Currently, the two most common drug classes used in medical expulsive therapy are calcium channel blockers and $\alpha_{1}$ - adrenoceptor antagonists, both are thought to act by inducing relaxation of the smooth muscle in the most common location of stone formation, the distal ureters and pelvic-ureteric junction to allow stone passage to the bladder [3, 4].

Alpha $_{1}(\alpha-1)$ adrenoreceptors (AR), $\alpha_{1} \mathrm{~A}$-adrenoceptor subtype, $\alpha_{1} \mathrm{~B}$-adrenoceptor subtypes and $\alpha_{1} \mathrm{D}$-adrenoceptor subtype distribution differs throughout the urinary system tract even possibly will be found in bladder and prostate [5]. The pathogenesis and medical therapy have been assigned to $\alpha_{1}$-adrenoceptors which induce contraction in the smooth muscle, while, $\alpha_{1}$ blockers may improve the relaxation of the smooth muscle [6]. $\alpha$-blockers are commonly recommended as an initial choice in the smooth muscle for treatment of hypertension which complicated into dyslipidaemia, diabetes and prostate attack [7]. A sulphonamide derivative, tamsulosin is an $\alpha_{1}$-AR antagonist widely used throughout the world [8], and its uroselectivity for $\alpha_{1} \mathrm{~A}$ and $\alpha_{1} \mathrm{D}$, resulting in the smooth muscles relaxation of the lower ureter, ease of stone passing and pain relief [9]. Tamsulosin used as a spasmolytic medication during renal colic due to juxta vesical calculi which increases the rate of stone expulsion and decreases the time of expulsion and thus has been widely used [10]. Whether tamsulosin, an $\alpha$-blocker, affects decreasing spontaneous ureteral contractility with or without phenylephrine, an $\alpha$-agonist [11], tamsulosin utilization may cause orthostatic hypotension through vasorelaxation by blocking the $\alpha_{1}$-adrenoceptors [12]. Several $\alpha_{1}$ - AR antagonists that are variable in medicins, such as, alfuzosin, doxazosin, tamsulosin and silodosin, show inhibitory effects on contractions on isolated ureter of a diversity of species [13].

This current study aims to provide a helpful guide to further understand the underlining mechanisms of tamsulosin vascular actions, and its use as medications for stone passing by testing it on a goat's renal smooth muscle cells with emphases on the role of endothelium/NO, $\mathrm{PGI}_{2}$ and $\mathrm{EET}, \mathrm{Ca}^{++}$and $\mathrm{K}^{+}$channels in its relaxant effects.

\section{METHODS AND MATERIALS}

This study was conducted at (Health and Science Research Centre - Koya University). Renal artery of male goats are used throughout this study, the kidneys of freshly slaughtered male goats, weighting from (15-20 Kg) are immediately collected from (Koya slaughterhouse). Then they were immersed in freshly prepared Kreb's solution with 7.4 PH and aerated with $95 \% \mathrm{O}_{2}$ and $5 \% \mathrm{CO}_{2}$ at $37{ }^{\circ} \mathrm{C}$. The isolated renal artery was cleaned from adhering fat and blood. The dissected artery was cut into several rings $(2-4 \mathrm{~mm})$ in length and kept in the physiological saline prior to starting the experiments. The procedure which was described by Al-Habib and Shekha [14] is followed with some changes to study the vascular reactivity in the isolated renal artery. Two stainless steel wire was carefully placed into lumen of the artery rings, one of them was anchored to a glass organ bath and the other wire was linked to force transducer, coupled to the trans bridge amplifier, and (AD Instrument Power Lab 26T Data Acquisition system) with computer running chart software (LabChart Version8)was used for measurement isometric tension of the isolated renal artery rings.

Prior to the experiment, the organ bath was filled with double distilled water and the temperature was set at $37^{\circ} \mathrm{C}$ for $(60-90 \mathrm{~min})$, followed by the addition of $(10 \mathrm{ml})$ of Kreb's solution (in mM/L: $118 \mathrm{NaCl}, 4.7 \mathrm{KCl}, 25 \mathrm{NaHCO}_{3}, 1.2 \mathrm{KH}_{2} \mathrm{PO}_{4}, 1.2 \mathrm{MgSO}_{4}, 2.4 \mathrm{CaCl}_{2}, 11$ 
Glucose and 0.03 EDTA) or free Calcium Kreb’s solution to each channel of the organ bath [15].

The preparation was oxygenated continuously with $\left(95 \% \mathrm{O}_{2}\right.$ and $\left.5 \% \mathrm{CO}_{2}\right)$. The temperature of the solution inside the organ bath was maintained $37^{\circ} \mathrm{C}$ by circulating water through water jacket from a circulating water bath set at $37{ }^{\circ} \mathrm{C}$ (Thermo circulator LabTech DAIHAN LABTECH CO., LTD.).

The primary tension was set at (2 gm) weight. Renal artery rings were allowed to equilibrate (60-90 $\mathrm{min}$ ) with buffer solution change every (15 min). For the integrity of functions the prepared artery segments, $\mathrm{KCl}(60 \mathrm{mM})$ [16], was used and the maximum contraction developed was considered as standard percentage contractile response. After the maximum contraction by $\mathrm{KCl}$ was reached to plateau, the renal artery rings were washed and restabilized at the optimum tension for at least ( $30 \mathrm{~min}$ ) before applying any vasoactive substances [17]. When tension had stabilized isometrically, concentration-response curves (CRCs) for $\mathrm{PE}\left(1 \times 10^{-5} \mathrm{M}\right)$ and $\mathrm{KCl}(60 \mathrm{mM})$ were constructed against induced contraction and then the experiments started.

\section{Experimental procedure}

The experimental procedure of experiments includes, the recording of normal mechanical activity of renal artery smooth muscles, and studying the effects of potassium chloride ( $\mathrm{KCl}$ ) and phenylephrine (PE) on normal mechanical activity of the goat renal artery smooth muscle within Kreb's solution, in addition to the effect of free $\mathrm{Ca}^{++}$Kreb's solution. Then the role of endothelial nitric oxide (NO), prostaglandin $\mathrm{I}_{2}\left(\mathrm{PGI}_{2}\right)$ and EET in the association with vasorelaxation induced by different doses of the tamsulosin $\left(1 \times 10^{-3}-10^{-8} \mathrm{M}\right)$ were studied following after incubation intact renal artery rings for $(10 \mathrm{~min})$ separately with each of $\mathrm{NO}$ synthase inhibitor (L-Name $\left.\left(3 \times 10^{-4} \mathrm{M}\right)\right), \mathrm{PGI}_{2}$ inhibitor (Indomethacin $\left(3 \times 10^{-5} \mathrm{M}\right)$ ) and EET (Clotrimazole $\left.\left(3 \times 10^{-5} \mathrm{M}\right)\right)$ and contracted with PE $\left(1 \times 10^{-5} \mathrm{M}\right)$. Also the role of Potassium channels $\left(\mathrm{K}^{+}\right.$channel) and calcium channels $\left(\mathrm{Ca}^{++}\right.$channel) in the development of vasorelaxation induced by different doses of Tamsulosin $\left(1 \times 10^{-3}-10^{-8} \mathrm{M}\right)$ were also studied by preincubation of the renal artery rings separately with each of the following potassium channel blockers, $\mathrm{K}_{\mathrm{Ca}}$ channel blocker $(\mathrm{TEA}(1 \mathrm{mM}))$, $\mathrm{K}_{\mathrm{ATP}}$ channel blocker (GLIB $\left(1 \times 10^{-5}\right.$ $\mathrm{M})$ ), $\mathrm{K}_{\mathrm{IR}}$ channel blocker $\left(\mathrm{BaCl}_{2}(1 \mathrm{mM})\right)$ and $\mathrm{K}_{\mathrm{V}}$ channel blocker (4-AP $(1 \mathrm{mM})$ ) and contracted with PE $\left(1 \times 10^{-5} \mathrm{M}\right)$, and in the free $\mathrm{Ca}^{++}$solution either the L-type calcium channel blocker Nifedipine (Nif. $1 \times 10^{-5}$ and $3 \times 10^{-5} \mathrm{M}$ ) or the $\mathrm{a}_{1}$-AR antagonist Tamsulosin (Tam. 1 $\times 10^{-5}$ and $3 \times 10^{-5} \mathrm{M}$ ) were used for testing the role of the $\mathrm{Ca}^{++}$channels.

\section{Statistical analysis}

The data of this study were expressed as $\mathrm{M} \pm \mathrm{SE}$ and the effective mean concentrations ( $\mathrm{IC}_{50}$ and $\mathrm{EC}_{50}$ ) were given as geometric mean with (95\%) confidence intervals (CI) and the potency values were described as the negative logarithm $\left(-\log \mathrm{IC}_{50}=\mathrm{pIC}_{50}\right.$ and $-\operatorname{logEC_{50}}=$ $\mathrm{pEC}_{50}$ ) of the mean of individual values for each tissue. For comparison between means of two groups two-way analysis of variance (Two-way ANOVA) was used supported by Sidak's multiple comparisons test, the concentration-response curve was analysed by non-linear regression. Probability of less than $0.05(\mathrm{p}<0.05)$ was considered as statistically significant, in all figures and tables, the symbols $*, * *, * * *$ and $* * * *$ indicate that the difference between means is significant at $0.05,0.01,0.001$ and $<0.0001$ levels, respectively. All the graphs, calculations and statistical analysis were done by GraphPad Prism software version 7.04 for windows, (GraphPad Software, USA). The maximum effect of relaxation ( $E_{\text {max. }}$ ) was considered as a maximal amplitude response reached in concentration-effects for relaxant agent. 


\section{RESULTS}

\section{Effect of Tamsulosin in renal artery rings}

The Tamsulosin $\left(1 \times 10^{-8}-1 \times 10^{-3} \mathrm{M}\right)$ exert relaxant effect on PE- and KCl-induced contractions, with a more relaxant effect in the PE $\left(10^{-5} \mathrm{M}\right)$ when compared to its relaxant effect in $\mathrm{KCl}(60 \mathrm{mM})$ precontracted renal artery rings (Figure 1$)$. The $\mathrm{pIC}_{50}$, $\left(\log \mathrm{IC}_{50}\right.$ of CI 95\%) and $\mathrm{E}_{\max }$ are shown in (Table1). Tamsulosin formed a most potent inhibitory effect on PE-and KCl-induced contractions in renal artery rings with a $\mathrm{pIC}_{50}$ of $6.878 \mathrm{mg} / \mathrm{mL}$, ( $\mathrm{Log}$ IC50 of CI 95\% between -7.238 to -6.452) and $7.362 \mathrm{mg} / \mathrm{mL}$ (Log IC50 of CI 95\% between 7.995 to -6.805$)$, respectively. The $\mathrm{E}_{\max }(\%)$ of renal artery rings contracted with PE reduced to only $102.015 \pm 2.024 \%$, while in renal artery rings precontracted with $\mathrm{KCl}$, the relaxation response was diminished as indicated by the increased contraction tone to $81.86 \pm 3.588 \%$.
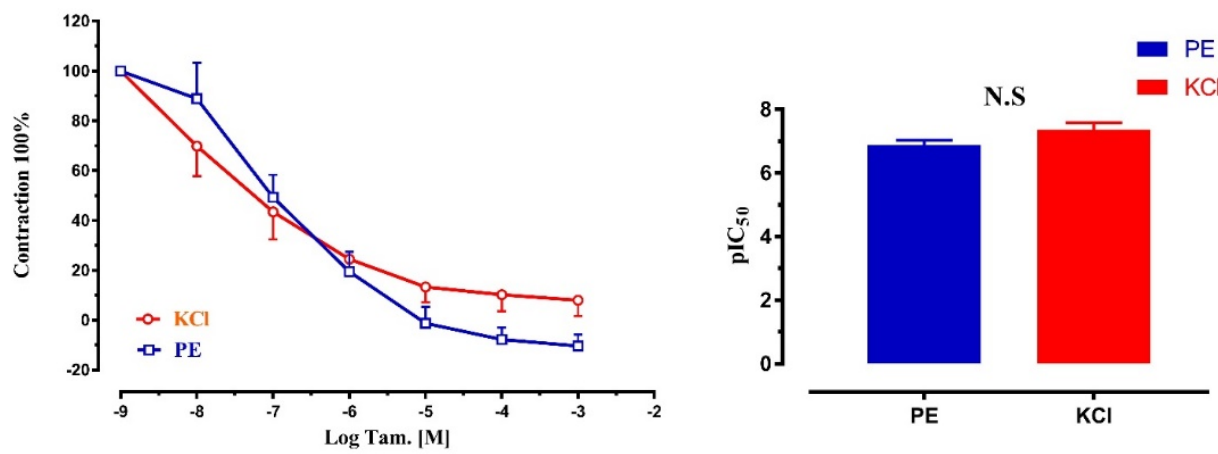

Figure 1: Cumulative dose-response curve of the effects of Tamsulosin on PE $\left(10^{-5}\right)$ and $\mathrm{KCl}(60 \mathrm{mM})$ precontracted renal artery rings. Left panel: lines represent 4 parameters logistic curve which calculate the variable, $\mathrm{pIC}_{50}$ and $\mathrm{E}_{\max }$.

Table 1: The pIC 50 (Log IC 50 of CI 95\%) and $E_{\max }(\%) \pm$ SEM for the effects of Tamsulosin on PE- and $\mathrm{KCl}$ precontracted renal artery rings.

\begin{tabular}{|c|c|c|}
\hline Treatments & \multicolumn{2}{|c|}{ Tamsulosin } \\
\hline Control & $\mathrm{PE}\left(10^{-5} \mathrm{M}\right)$ & $\mathrm{KCl}(60 \mathrm{mM})$ \\
\hline $\mathrm{pIC}_{50}$ & 6.878 & 7.362 \\
\hline Log IC $_{50}$ of CI $95 \%$ & -7.238 to -6.452 & -7.995 to -6.805 \\
\hline $\mathrm{E}_{\max }(\%) \pm$ SEM & $102.015 \pm 2.024$ & $81.86 \pm 3.588$ \\
\hline
\end{tabular}

\section{Role of Potassium chan. in the vasorelaxant effect of Tamsulosin}

To investigate the role of potassium channels in the vasorelaxant effect of tamsulosin in renal artery rings, the rings have been preincubated for 10 minutes with TEA $(1 \mathrm{mM})$, Glib. $\left(10^{-5}\right)$, $\mathrm{BaCl}_{2}(1 \mathrm{mM})$ and 4-AP $(1 \mathrm{mM})$ individually, which are the blockers of $\mathrm{K}_{\mathrm{Ca}}, \mathrm{K}_{\mathrm{ATP}}, \mathrm{K}_{\mathrm{IR}}$ and $\mathrm{K}_{\mathrm{V}}$ channels respectively. Their relaxant effects were recorded. Dose-response curves for the effect of Tam. against PE-induced contractions and preincubated with the potassium channel blockers are shown in (Figures 2, 3, 4 and 5). The pre-treatment of renal artery rings with either Glib or 4-AP showed a slight shift to the right, while in TEA and $\mathrm{BaCl}_{2}$ remained 
unchanged. Tam. concentrations $\left(10^{-8}\right.$ to $\left.10^{-3} \mathrm{M}\right)$ caused a potent relaxation on $\mathrm{PE}\left(10^{-5} \mathrm{M}\right)$ precontracted goat renal artery rings. (Table2) shows, the $\mathrm{pIC}_{50}$, (LogIC $\mathrm{L}_{50}$ of $\left.\mathrm{CI} 95 \%\right)$ and $\mathrm{E}_{\max }$ (\%) for the effect of $\mathrm{K}^{+}$channel inhibitors on the relaxant response to Tamsulosin in goat's renal artery rings.

Pre-treatment of renal artery rings with Glib or 4-AP significantly reduced the relaxation, with $\mathrm{pIC}_{50} 5.783 \mathrm{mg} / \mathrm{ml}$, (LogIC 50 of CI 95\% between -6.362 to -5.134$)$ and $6.373 \mathrm{mg} / \mathrm{ml}(-7.264$ to -5.48$)$, and also they reduce the percentage of relaxation to $83.14 \pm 0.519 \%$ and $75.31 \pm$ $0.915 \%$, respectively, as compared to the control which was $102.015 \pm 2.024 \%$.
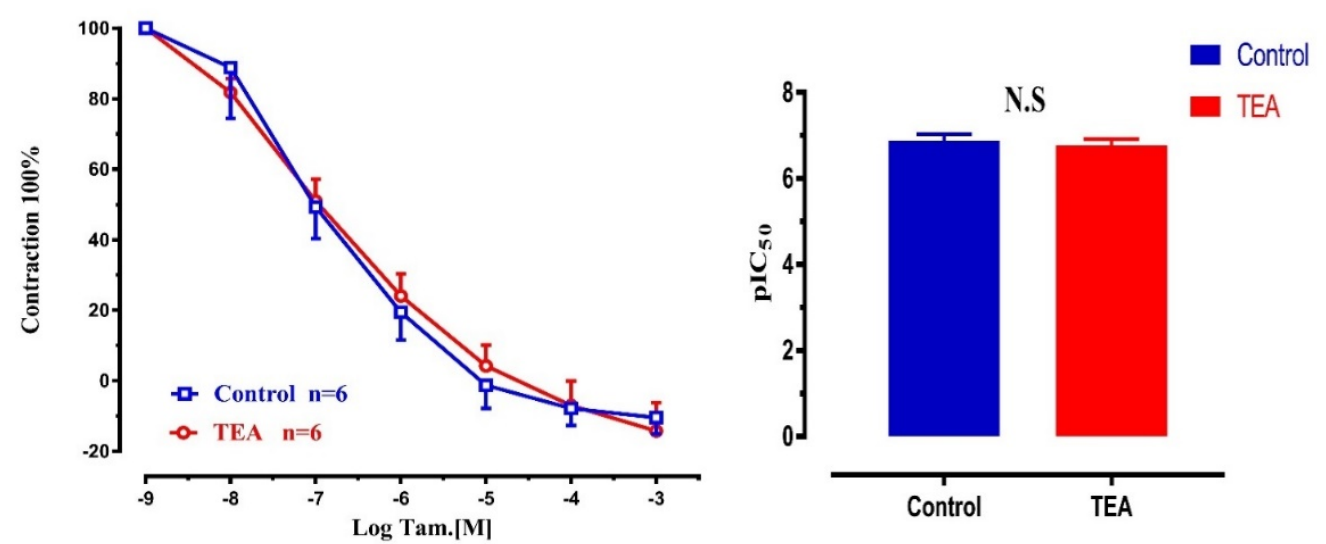

Figure 2: Cumulative dose-response curves of the vasorelaxant effects of Tam. On control and preincubated renal artery rings with TEA $(1 \mathrm{mM})$, precontracted with PE $\left(1 \times 10^{-5} \mathrm{M}\right)$. Left panel: lines represent 4 parameters logistic curve which calculate the variable, pIC50 and Emax.
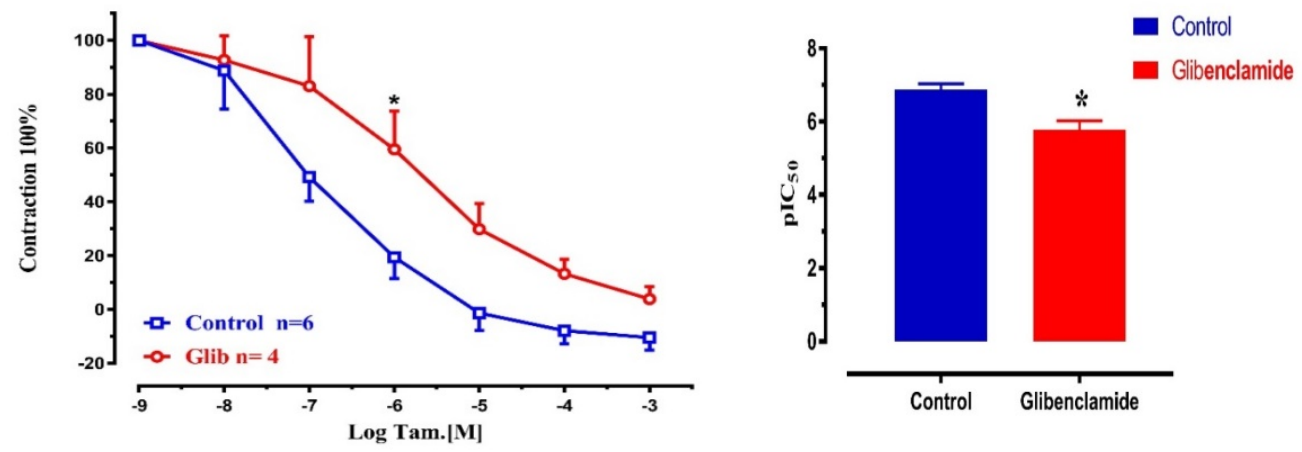

Figure 3: Cumulative dose-response curves of the vasorelaxant effects of Tam. On control and preincubated renal artery rings with Glib $\left(1 \times 10^{-5} \mathrm{M}\right)$, precontracted with PE $\left(1 \times 10^{-5} \mathrm{M}\right)$. Left panel: lines represent 4 parameters logistic curve which calculate the variable, $\mathrm{pIC}_{50}$ and $\mathrm{E}_{\max }$. 

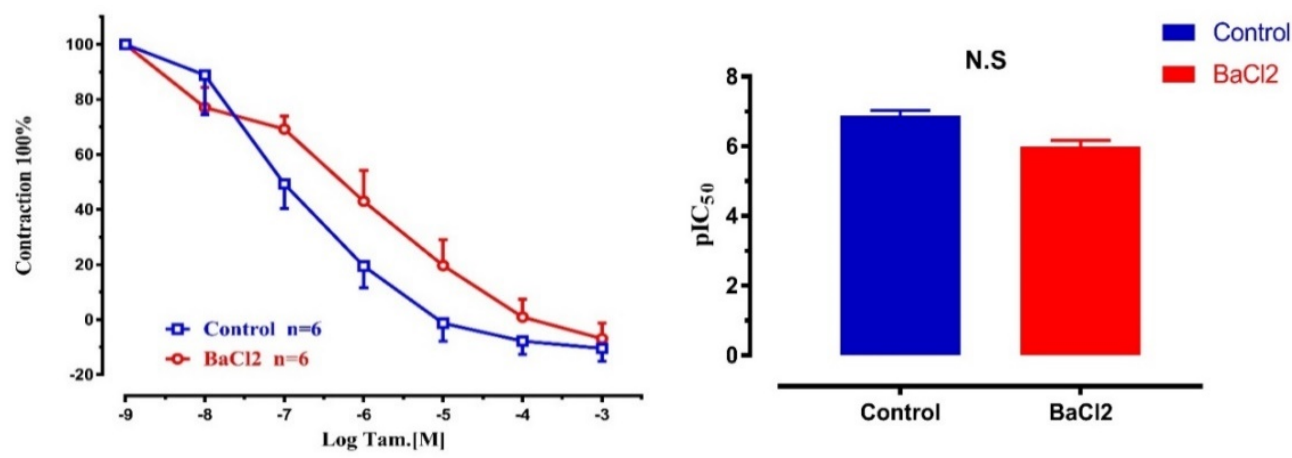

Figure 4: Cumulative dose-response curves of the vasorelaxant effects of Tam. On control and preincubated renal artery rings with $\mathrm{BaCl}_{2}(1 \mathrm{mM})$, precontracted with $\mathrm{PE}\left(1 \times 10^{-5} \mathrm{M}\right)$. Left panel: lines represent 4 parameters logistic curve which calculate the variable, $\mathrm{pIC}_{50}$ and $\mathrm{E}_{\max }$.
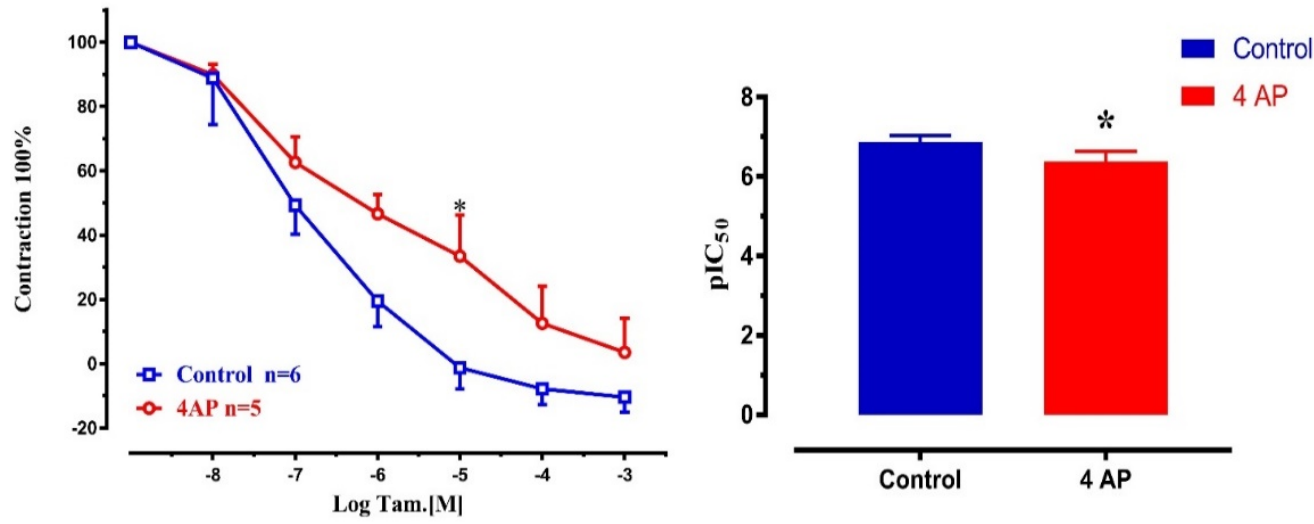

Figure 5: Cumulative dose-response curves for the vasorelaxant effects of Tam. On control and preincubated renal artery rings with 4AP $(1 \mathrm{mM})$, precontracted with PE $\left(1 \times 10^{-5} \mathrm{M}\right)$. Left panel: lines represent 4 parameters logistic curve which calculate the variable, pIC50 and Emax.

\section{Role of endothelium/NO, PGI $\mathrm{I}_{2}$ and EET in the vasorelaxant effect of Tamsulosin}

The percentage of relaxation, $\mathrm{pIC}_{50}$, and $\left(\operatorname{LogIC}_{50}\right.$ of $\left.\mathrm{CI} 95 \%\right)$ for the relaxant response to tamsulosin were highly significant in renal artery rings preincubated with clotrimazole and slightly with Indomethacin compared to the control rings (Figures 6, 7 and 8), with pIC $_{50}$ $5.961 \mathrm{M}$, and ( $\operatorname{LogIC}_{50}$ of CI 95\% between -6.928 to -5.208 ) and $6.056 \mathrm{M}$ (withLogIC ${ }_{50}$ of CI 95\% between -6.663 to -5.522 ) and Emax were $60.56 \pm 0.061$ and $76.67 \pm 0.1$, respectively. While L-Name pre-treatments did not change the relaxation induced by Tamsulosin (Table 2). 

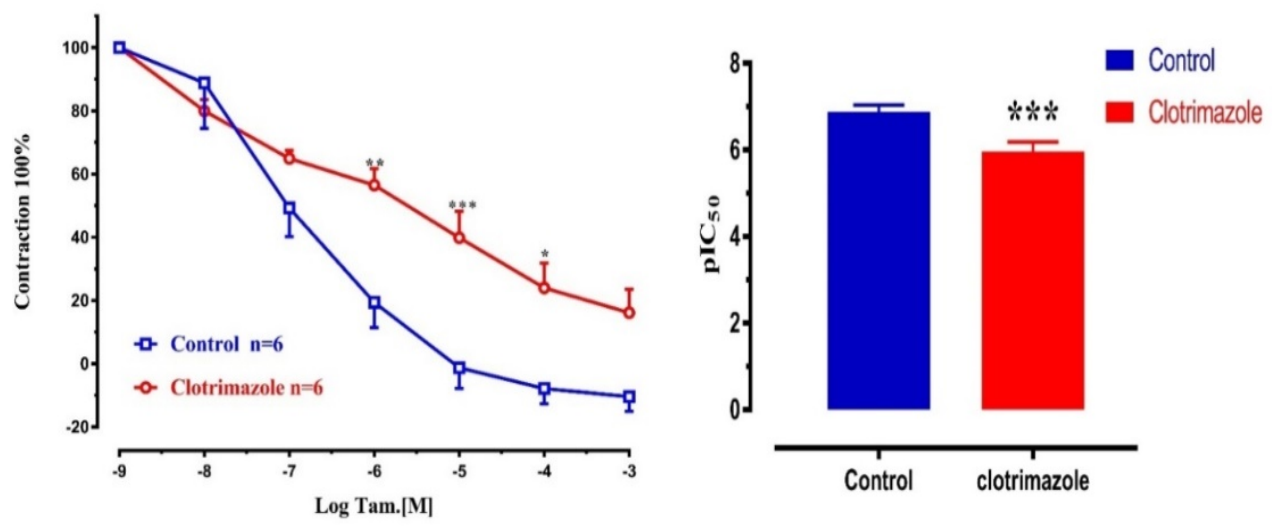

Figure 6: Cumulative dose-response curve for the vasorelaxant effects of Tam. on control and preincubated renal artery rings with Clotrimazole $\left(3 \times 10^{-5} \mathrm{M}\right)$, precontracted with PE $\left(10^{-5} \mathrm{M}\right)$. Left panel: lines represent 4 parameters logistic curve which calculate the variable, pIC $\mathrm{C}_{50}$ and $\mathrm{E}_{\max }$.
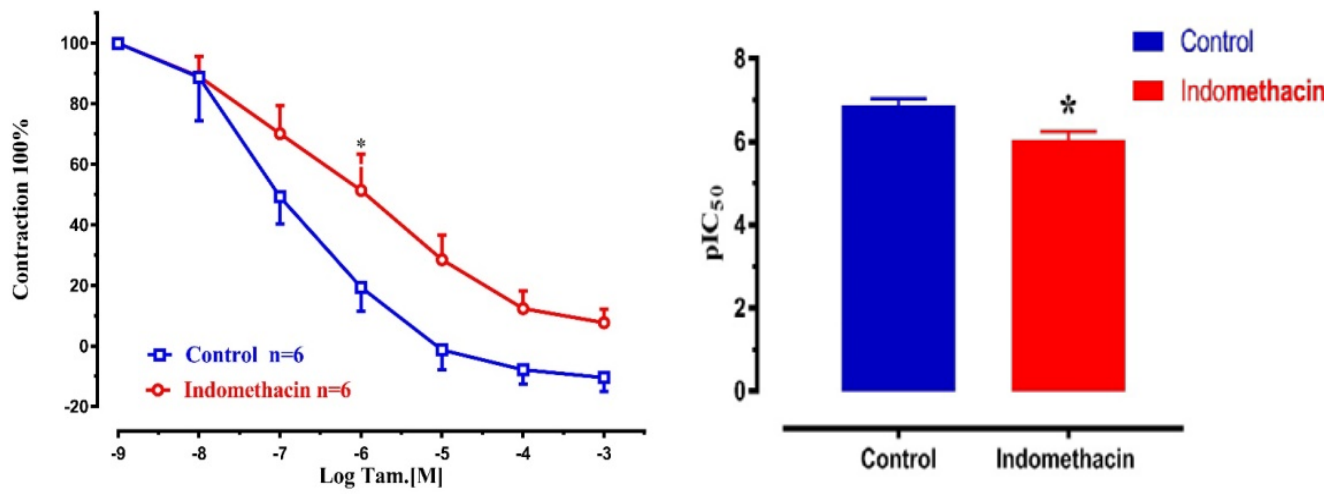

Figure 7: Cumulative dose-response curve for the vasorelaxant effects of Tam. on control and preincubated renal artery rings with Indomethacin $\left(3 \times 10^{-5} \mathrm{M}\right)$, precontracted with PE $\left(10^{-5} \mathrm{M}\right)$. Left panel: lines represent 4 parameters logistic curve which calculate the variable, pIC50 and $\mathrm{E}_{\max }$. 

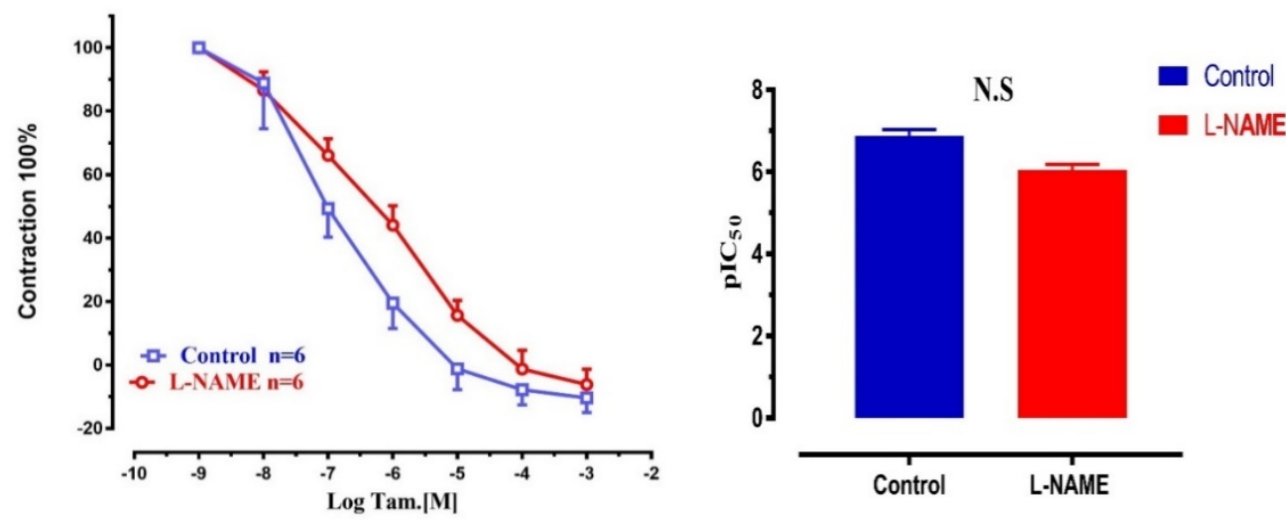

Figure 8: Cumulative dose-response curve for the vasorelaxant effects of Tam. on control and preincubated renal artery rings with L-Name $\left(3 \times 10^{-4} \mathrm{M}\right)$, precontracted with PE $\left(10^{-5} \mathrm{M}\right)$. Left panel:

lines represent 4 parameters logistic curve which calculate the variable, $\mathrm{pIC}_{50}$ and $\mathrm{E}_{\max }$.

Table 2: The pIC50 (Log IC50 of CI 95\%) and $E_{\max }(\%) \pm$ SEM for the effects of Tamsulosin after incubation of renal artery with $\mathrm{K}^{+}$channel blockers, clotrimazole, indomethacin and L-Name.

\begin{tabular}{|c|c|c|c|c|}
\hline Treatments & NO. & pIC50 & LogIC50 of CI 95\% & $E_{\max }(\%) \pm$ SEM \\
\hline Control & 6 & $6.878 \pm 0.1572$ & -7.238 to -6.452 & $102.015 \pm 2.024$ \\
\hline TEA & 6 & $6.768 \pm 0.15$ & -7.144 to -6.29 & $96.323 \pm 1.568$ \\
\hline Glib. & 4 & $5.783 \pm 0.241$ & -6.362 to -5.134 & $\mathbf{8 3 . 1 4} \pm \mathbf{0 . 5 1 9} *$ \\
\hline $\mathrm{BaCl}_{2}$ & 6 & $5.994 \pm 0.1796$ & -6.47 to -5.509 & $84.471 \pm 0.011$ \\
\hline 4Ap & 5 & $6.373 \pm 0.2613$ & -7.264 to -5.48 & $\mathbf{7 5 . 3 1} \pm \mathbf{0 . 9 1 5} *$ \\
\hline Clotrimazole & 6 & $5.961 \pm 0.2198$ & -6.928 to -5.208 & $\mathbf{6 0 . 5 6} \pm \mathbf{0 . 0 6 1}$ \\
\hline *** \\
\hline Indomethacin & 6 & $6.056 \pm 0.1985$ & -6.663 to -5.522 & $\mathbf{7 6 . 6 7 \pm \mathbf { 0 . 1 }} *$ \\
\hline L- Name & 6 & $6.051 \pm 0.1295$ & -6.408 to -5.724 & $88.841 \pm 0.068$ \\
\hline
\end{tabular}

\section{Role of $\mathrm{Ca}^{2+}$ channels in Tam. vasorelaxant effect of $\mathrm{CaCl}_{2}$ induced contraction}

Both doses of Tam. $\left(1 \times 10^{-5}\right.$ and $\left.3 \times 10^{-5} \mathrm{M}\right)$ produced highly significant $(\mathrm{P}<0.0001)$ vasoconstriction effects on $\mathrm{CaCl}_{2}$ induced dose-dependent contraction in renal artery rings pre-incubated with Tam. as compared to the control (Figure 9). The $\mathrm{pEC}_{50}$, (LogEC $\mathrm{L}_{50}$ of CI 95\%) and the maximum contraction are shown in (Table3). Both Tam. doses $\left(1 \times 10^{-5}\right.$ and $3 \times 10^{-5} \mathrm{M}$ ) showed highly significant effects on $\mathrm{CaCl}_{2}$ contracted goat artery rings with $\mathrm{PEC}_{50}$ 2.847M (LogEC50 of CI 95\% between -3.176 to -2.48) and 2.53 M (LogEC50 of CI 95\% between -3.079 to -2.546$)$, and the maximum contraction $(49.213 \pm 3.327)$ and $(54.084 \pm$ 3.311) respectively. 

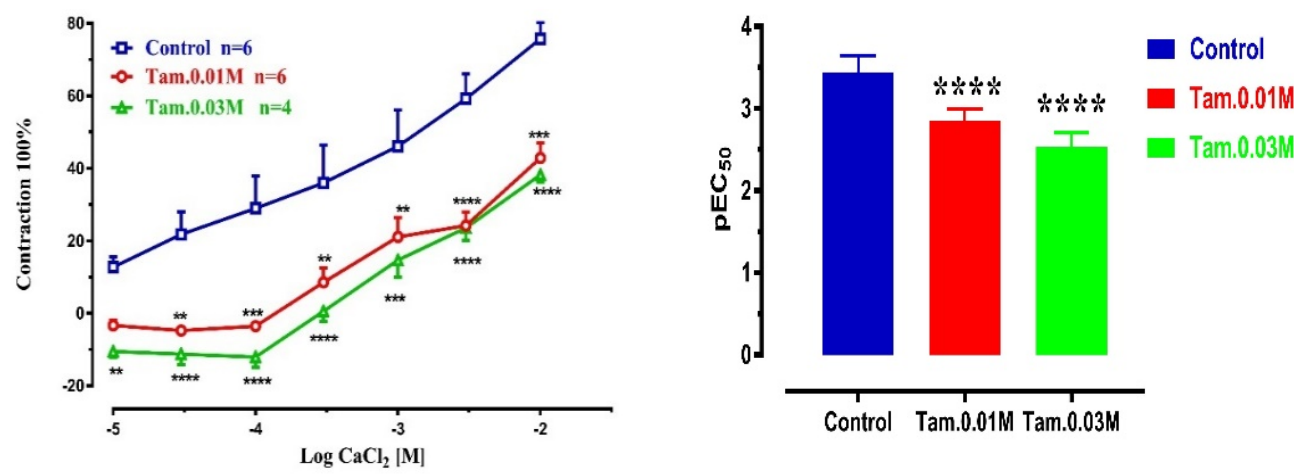

Figure 9: Cumulative dose-response curves of $\mathrm{CaCl}_{2}$ in renal artery rings pre-incubated with different doses of Tam. $\left(1 \times 10^{-5} \mathrm{mg} / \mathrm{ml}-3 \times 10^{-5} \mathrm{mg} / \mathrm{ml}\right)$. Left panel: lines represent 4 parameters logistic curve which calculate the variable, pEC50 and Emax.

\section{Effect of Nifedipine on renal artery rings contraction induced by $\mathrm{CaCl}_{2}$}

Both doses of Nifedipine $\left(1 \times 10^{-5}\right.$ and $\left.3 \times 10^{-5} \mathrm{M}\right)$ produced highly significant $(\mathrm{P}<0.0001)$ vasoconstriction effects on $\mathrm{CaCl}_{2}$ induced dose-dependent contraction in renal artery rings pre-incubated with Nifedipine as compared to the control (Figure 10). The $\mathrm{pEC}_{50}$, (LogEC $\mathrm{L}_{50}$ of CI 95\%) and the maximum contraction are shown in (Table 3). Both Nifedipine doses $\left(1 \times 10^{-5}\right.$ and $3 \times 10^{-5} \mathrm{M}$ ) showed highly significant effects on $\mathrm{CaCl}_{2}$ contracted goat artery rings with pEC $_{50} 2.567 \mathrm{M}$ (Log EC50 of CI 95\% between -2.808 to -2.325) and 2.628 M (LogEC50 of CI $95 \%$ between -2.986 to -2.214$)$, and the maximum contraction $(46.123 \pm 3.184)$ and $(46.371 \pm 4.705)$ respectively.
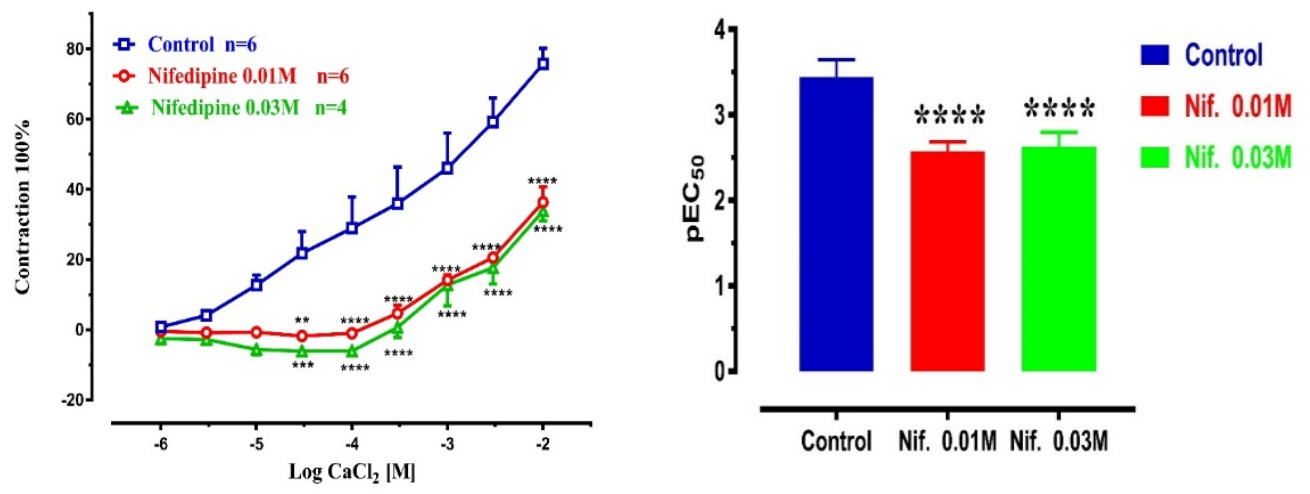

Figure 10: Cumulative dose-response curves of $\mathrm{CaCl}_{2}$ in renal artery rings pre-incubated with different doses of Nifedipine $\left(1 \times 10^{-5} \mathrm{mg} / \mathrm{ml}-3 \times 10^{-5} \mathrm{mg} / \mathrm{ml}\right)$. Left panel: lines represent 4 parameters logistic curve which calculate the variable, pEC50 and Emax. 
Table 3: The pEC50 (Log EC50 of CI 95\%) and $E_{\max }(\%) \pm$ SEM for the effects of Tam. and Nifedipine on preincubated renal artery rings with $\mathrm{CaCl}_{2}$.

\begin{tabular}{|c|c|c|c|c|c|}
\hline \multirow{2}{*}{ Treatments } & \multirow{2}{*}{ Control } & \multicolumn{2}{|c|}{ Tamsulosin } & \multicolumn{2}{c|}{ Nifedipine } \\
\cline { 3 - 6 } & & $0.01 \mathrm{M}$ & $0.03 \mathrm{M}$ & $0.01 \mathrm{M}$ & $0.03 \mathrm{M}$ \\
\hline No. & 6 & 6 & 4 & 6 & 4 \\
\hline \multirow{3}{*}{ pEC50 } & 3.442 & 2.847 & 2.53 & 2.576 & 2.628 \\
& \pm & \pm & \pm & \pm & \pm \\
& 0.2037 & 0.1472 & 0.1738 & 0.1079 & 0.1668 \\
\hline \multirow{3}{*}{ LogEC50 of CI 95\% } & -4.074 & -3.176 & -3.079 & -2.808 & -2.986 \\
& to & to & to & to & to \\
& -2.827 & -2.48 & -2.546 & -2.325 & -2.214 \\
\hline & 61.402 & $\mathbf{4 9 . 2 1 3}$ & $\mathbf{5 4 . 0 8 4}$ & $\mathbf{4 6 . 1 2 3}$ & $\mathbf{4 6 . 3 7 1}$ \\
\hline \multirow{2}{*}{ Emax (\%) \pm SEM } & \pm & \pm & \pm & \pm & \pm \\
& 2.318 & $\mathbf{3 . 3 2 7} * * * *$ & $\mathbf{3 . 3 1 1} * * * *$ & $\mathbf{3 . 1 8 4 8} * * * *$ & $\mathbf{4 . 7 0 5} * * * *$ \\
\hline
\end{tabular}

\section{DISCUSSION}

\section{The vasorelaxant effect of Tamsulosin on isolated renal artery rings}

The current study represents the first detailed investigation on concentration-dependent vasorelaxation of tamsulosin in the renal artery. Several scientific trials have study use of the $\mathrm{a}_{1}$ A/D-selective $\alpha$-blockers such as tamsulosin and others, showed their benefits in enhancing stone removal. Previous studies reported the efficient action of various alpha-blockers on the relaxation of the ureter wall and many undesirable effects at the circulatory level [13].

The outcome of the present research demonstrated that the cumulative addition of tamsulosin exhibited greater relaxant effects on the contractions induced by $\mathrm{PE}$ than by $\mathrm{KCl}$. The vasorelaxant effect of tamsulosin decreased with $\mathrm{KCl}$ - induced vasoconstriction. The tamsulosin-induced vasodilation was attenuated by the constriction caused by PE.

Previously demonstrated that binding of $\mathrm{PE}$ to $\mathrm{a}_{1} \mathrm{~A}$-adrenoceptors leads to an activation of the Phospholipase C (PLC) that generates the second messenger IP3, that causes a release of $\mathrm{Ca}^{2+}$ from $\mathrm{IP}_{3}$ sensitive stores, then rising $\left[\mathrm{Ca}^{2+}\right] \mathrm{i}$ results in a further increase of $\left[\mathrm{Ca}^{2+}\right] \mathrm{i}$ due to $\mathrm{Ca}^{2+}$ liberation from the $\mathrm{Ca}^{2+}$-sensitive $\mathrm{Ca}^{2+}$ pools and to an augmented $\mathrm{Ca}^{2+}$ entry through L-type $\mathrm{Ca}^{2+}$ channels [18].

Some researchers showed that the in vivo contractions of dog [19], and invitro contraction of rat [20], the smooth muscle of prostate induced by epinephrine and phenylephrine are inhibited by tamsulosin. Moreover, the contractions resulted by phenylephrine in the human prostate smooth muscle are blocked by increasing the concentration of tamsulosin, others mentioned that the contractions by phenylephrine in the dog bladder prevented by tamsulosin competitively [21].

Also Troxel, et al. [22], found that the addition of tamsulosin blocks the stimulatory effect of phenylephrine. Previously mentioned that, contractions of the rat tail [23], and mesenteric artery [24], induced by phenylephrine or noradrenalin were semi completely prevented by tamsulosin as compared to the effects of other alpha-adrenergic antagonists, such as prazosin, phentolamine, and tamsulosin hydrochloride may cause facilitate flow of urine by inhibition of alpha-adrenergic receptors in diverse species [21]. 
The result of the current study regarding the renal artery supports the previous findings for the contraction inhibitory of tamsulosin in other tissues; this may be due to the presence of the receptors in the renal artery.

\section{Role of $\mathrm{K}^{+}$channels in Tam. relaxant effect}

Pre-treatment of renal artery rings with potassium channel blockers, Glib and 4-AP, showed significant enhancement in the vasorelaxant effect of tamsulosin, while there were no changes in the vasorelaxation effect of Tam. in pre-treated with TEA and $\mathrm{BaCl}_{2}$. The findings of the study support the previous study demonstrated that in rat lung, 4-AP and TEA as an effective vasoconstrictor, and 4-AP caused biphasic pressor responses. The portion of contraction inhibited by phentolamine, adrenergic alpha-receptor blocking drug, could be caused either by catecholamines release or possibly the direct binding of TEA and 4-AP to $\alpha$-adrenoceptors, whereas an increase in the relaxant vascular effect of tamsulosin was observed concerning $\mathrm{BaCl}_{2}[25]$.

The results of the current study on tamsulosin exhibited a statistically significant dosedependent vasodilation with Glib and 4-AP. These findings show that the vasodilatory responses of tamsulosin are mediated through a negative role of $\mathrm{K}_{\mathrm{ATP}}$ and $\mathrm{K}_{\mathrm{V}}$ channels.

\section{Role of NO, PGI2 and EET in Tamsulosin relaxant effect}

Tamsulosin-induced vasodilation was enhanced by preincubation of renal artery rings with Indomethacin, a prostaglandin $\mathrm{I}_{2}$ inhibitor or Clotrimazole, an epoxyeicosatrienoic acid inhibitor, while it did not alter by preincubation with oxide synthase inhibitor, L-Name. This indicates that vasoactive substance release from endothelium (NO) does not play any role in the vasodilation induced by tamsulosin in precontracted renal artery rings with PE. Previously stated that clotrimazole selectively inhibits cytochrome- $\mathrm{P}_{450}$ it is reasonable to interfere with the biosynthesis of the vasoactive agents produced by the endothelial or VSMCs [26]. Also, clotrimazole inhibits pathways of COX and synthesis of $\mathrm{TXA}_{2}$ in different cellular systems by suppressing the cytochrome- $\mathrm{P}_{450}$-dependent pathways of arachidonic acid metabolism [27]. Moreover, clotrimazole inhibits the transportation of calcium in isolated tissues through inhibiting of SERCA-ATPase and decreasing the contractile ability through reducing the affinity of SERCA to calcium ions $[17,28]$.

\section{Role of $\mathrm{Ca}^{++}$channel blockers in Tam. relaxant effect}

In the present research, the nifedipine and tamsulosin significantly enhance the relaxation rate in renal artery rings. These results match the previous study stated that $\mathrm{Ca}^{2+}$-channel blockers reduced significantly the phasic contractions of the ureter tissue induced by electrical field stimulation, with nifedipine being the most potent agent, this indicates that nifedipine significantly cause ureteric relaxation of the smooth muscle in vitro [11]. $\alpha_{1} \mathrm{~A}$-adrenoceptor blocker and $\mathrm{Ca}^{++}$channel blocker produce effective relaxation of the smooth muscle [29].

Nifedipine exerts its effect directly on smooth muscle cells by inhibiting calcium influx into the cell via inhibition of L-type $\mathrm{Ca}^{2+}$ channels [30], thus preventing binding of intracellular calcium to calmodulin and eventually inhibiting contractions. Hence, it is widely used as a tocolytic for preterm labour since it decreases uterine smooth muscle contractions [31]. Tamsulosin blocks $\alpha-{ }_{1} \mathrm{~A} /{ }_{1} \mathrm{D}$ receptors in the bladder and ureter, thus preventing calcium influx into the cell and causing smooth muscle cell relaxation [32, 33].

Calcium channel blockers lower contractions level of smooth muscle and decrease spasm in the ureter, meanwhile $\alpha-1$ adrenergic blockers lowered muscle tone of the ureter [34]. Some 
researchers showed that $\mathrm{Ca}^{++}$channels permit the transport of extracellular calcium into the cell, which returns the ureteral peristalsis to the normal levels. Some studies revealed that nifedipine and verapamil inhibit these contractions. Similarly, another's used human caliceal rings which show the spontaneous phasic-rhythmic activity inhibition of the upper urinary tract by calcium channel blockers [22].

\section{CONCLUSION}

From the present study outcomes, it was found that tamsulosin has a relaxant effect in the renal artery and this result is the first record of this drug in the renal artery. Additionally, tamsulosin block potassium and calcium channels, which are mediated possibly through blocking of $\mathrm{K}_{\mathrm{V}}, \mathrm{K}_{\mathrm{ATP}}, \mathrm{PGI}_{2}$, EET and voltage-dependent calcium channels.

\section{REFERENCES}

[1] T. Campschroer, X. Zhu, R. W. Vernooij, and M. T. Lock, "Alpha-blockers as medical expulsive therapy for ureteral stones," Cochrane Database of Systematic Reviews, no. 4, 2018.

[2] A. C. Meltzer et al., "Effect of tamsulosin on passage of symptomatic ureteral stones: a randomized clinical trial," JAMA internal medicine, vol. 178, no. 8, pp. 1051-1057, 2018.

[3] D. Bos and A. Kapoor, "Update on medical expulsive therapy for distal ureteral stones: Beyond alphablockers," Canadian Urological Association Journal, vol. 8, no. 11-12, p. 442, 2014.

[4] E. El-Barky, Y. Ali, M. Sahsah, A. A. Terra, and E. O. Kehinde, "Site of impaction of ureteric calculi requiring surgical intervention," Urolithiasis, vol. 42, no. 1, pp. 67-73, 2014.

[5] O. R. Karabacakb et al., "Alpha adrenergic receptors in renal pelvis and calyces: can rat models be used?," International braz j urol, vol. 40, no. 5, pp. 683-689, 2014.

[6] M. Hennenberg et al., "Non-Adrenergic, Tamsulosin-Insensitive Smooth Muscle Contraction is Sufficient to Replace $\alpha 1$-Adrenergic Tension in the Human Prostate," The Prostate, vol. 77, no. 7, pp. 697-707, 2017.

[7] M. Kaplan, "Alpha-blockers in the Treatment of Hypertension," NEFROLOGÍA, vol. XX, 2000. nifedipine for distal ureteral calculi: a meta-analysis," Drug design, development and therapy, vol. 10, p. 1257, 2016.

[9] A.-f. A.-m. Ahmed and A.-y. S. Al-sayed, "Tamsulosin versus alfuzosin in the treatment of patients with distal ureteral stones: prospective, randomized, comparative study," Korean journal of urology, vol. 51, no. 3, pp. 193-197, 2010.

[10] H. Krishnasamy, "A prospective study Research, 9,(11), 61523-61526," Key words, 2017.

[11] J. W. Lee, M. Y. Lee, and I. Y. Seo, "In-vitro study on ureteral smooth muscle contractility with tamsulosin, nifedipine, and terpene mixture (Rowatinex $\left.{ }^{\circledR}\right), "$ MINERVA UROLOGICA E NEFROLOGICA vol. 67, no. 2, pp. 91-96, 2015.

[12] M. F. Vrolijk, G. R. Haenen, A. Opperhuizen, E. H. Jansen, P. M. Schiffers, and A. Bast, "The supplement-drug interaction of quercetin with tamsulosin on vasorelaxation," European journal of pharmacology, vol. 746, pp. 132-137, 2015.

[13] L. Villa et al., "Effects by silodosin on the partially obstructed rat ureter in vivo and on human and rat isolated ureters," British journal of pharmacology, vol. 169, no. 1, pp. 230-238, 2013.

[14] O. A. Al-Habib and M. S. Shekha, "Vasorelaxant effect of aqueous extract of Crataegus azarolus aronia and quercetin on isolated albino rat's thoracic aorta," J Duhok Univ, vol. 13, pp. 1-9, 2010.

[15] I.-W. Shin et al., "Etomidate attenuates phenylephrine-induced contraction in isolated rat aorta," Canadian Journal of Anesthesia, vol. 52, no. 9, p. 927, 2005.

[16] Z. Qu et al., "Vasorelaxant effects of Cerebralcare Granule ${ }^{\circledR}$ are mediated by NO/cGMP pathway, potassium channel opening and calcium channel blockade in isolated rat thoracic aorta," Journal of ethnopharmacology, vol. 155, no. 1, pp. 572-579, 2014.

[17] A. Ahmed and I. Maulood, "The roles of potassium channels in contractile response to urotensin-II in mercury chloride induced endothelial dysfunction in rat aorta," Iranian Journal of Veterinary Research, vol. 19, no. 3, p. 208, 2018.

[18] R. Eckert, A. Karsten, J. Utz, and M. Ziegler, "Regulation of renal artery smooth muscle tone by $\alpha 1$ adrenoceptors: role of voltage-gated calcium channels and intracellular calcium stores," Urological research, vol. 28, no. 2, pp. 122-127, 2000.

[19] H. Kontani and C. Shiraoya, "Method for simultaneous recording of the prostatic contractile and urethral pressure responses in anesthetized rats and the effects of tamsulosin," The Japanese Journal of Pharmacology, vol. 90, no. 3, pp. 281-290, 2002. 
[20] L.-M. Tang, J.-T. Cheng, and Y.-C. Tong, "Inhibitory effect of buflomedil on prostate $\alpha 1 \mathrm{~A}$ adrenoceptor in the Wistar rat," Neuroscience letters, vol. 367, no. 2, pp. 224-227, 2004.

[21] A. Karadeniz, İ. Pişkin, D. Eşsiz, and L. Altintaş, "Relaxation Responses of Trigonal Smooth Muscle from Rabbit by Alpha 1-Adrenoceptor Antagonists Alfuzosin, Doxazosin and Tamsulosin," Acta Veterinaria Brno, vol. 77, no. 1, pp. 81-88, 2008.

[22] S. Troxel, A. Jones, L. Magliola, and J. Benson, "Physiologic effect of nifedipine and tamsulosin on contractility of distal ureter," Journal of endourology, vol. 20, no. 8, pp. 565-568, 2006.

[23] S. Jähnichen, M. Eltze, and H. H. Pertz, "Evidence that $\alpha 1$ B-adrenoceptors are involved in noradrenalineinduced contractions of rat tail artery," European journal of pharmacology, vol. 488, no. 1-3, pp. 157-167, 2004.

[24] P. H. Van der Graaf, N. P. Shankley, and J. W. Black, "Analysis of the activity of $\alpha 1$-adrenoceptor antagonists in rat aorta," British journal of pharmacology, vol. 118, no. 2, pp. 299-310, 1996.

[25] K. Hasunuma, D. M. Rodman, and I. F. Mcmurtry, "Effects of K+ Channel Blockers on Vascular Tone in the Perfused Rat Lung1-3," Am Rev Respir Dis, vol. 144, pp. 884-887, 1991.

[26] P. Crowley and H. Gallagher, "Clotrimazole as a pharmaceutical: past, present and future," Journal of applied microbiology, vol. 117, no. 3, pp. 611-617, 2014.

[27] P. Tep-Areenan and P. Sawasdee, "Vasorelaxant effects of 5, 7, 4'-trimethoxyflavone from Kaepmferia parviflora in the rat aorta," IJP-International Journal of Pharmacology, vol. 6, no. 4, pp. 419-424, 2010.

[28] C. Elam, M. Lape, J. Deye, J. Zultowsky, D. T. Stanton, and S. Paula, "Discovery of novel SERCA inhibitors by virtual screening of a large compound library," European journal of medicinal chemistry, vol. 46, no. 5, pp. 1512-1523, 2011.

[29] K. Davenport, A. G. Timoney, and F. X. Keeley, "A comparative in vitro study to determine the beneficial effect of calcium-channel and $\alpha 1$-adrenoceptor antagonism on human ureteric activity," BJU international, vol. 98, no. 3, pp. 651-655, 2006

[30] R. C. Young, R. Schumann, and P. Zhang, "Nifedipine block of capacitative calcium entry in cultured human uterine smooth-muscle cells," Journal of the Society for Gynecologic Investigation, vol. 8, no. 4, pp. 210-215, 2001.

[31] T. A. Manuck, "Pharmacogenomics of preterm birth prevention and treatment," BJOG: An International Journal of Obstetrics \& Gynaecology, vol. 123, no. 3, pp. 368-375, 2016.

[32] S. Sigala et al., "Evidence for the presence of $\alpha 1$ adrenoceptor subtypes in the human ureter," Neurourology and Urodynamics: Official Journal of the International Continence Society, vol. 24, no. 2, pp. 142-148, 2005.

[33] L. Haddad et al., "Impact of tamsulosin and nifedipine on contractility of pregnant rat ureters in vitro," The Journal of Maternal-Fetal \& Neonatal Medicine, vol. 31, no. 2, pp. 191-196, 2018

[34] V. P. Srivastava, C. P. Pandey, M. A. Raza, K. K. Agarwal, and C. Chauhan, "Effectiveness of alpha blockers+ corticosteroids in expulsion of ureteric stones: a clinical observation," International Journal of Medical Science and Public Health, vol. 3, no. 6, pp. 693-696, 2014. 
APPENDIX
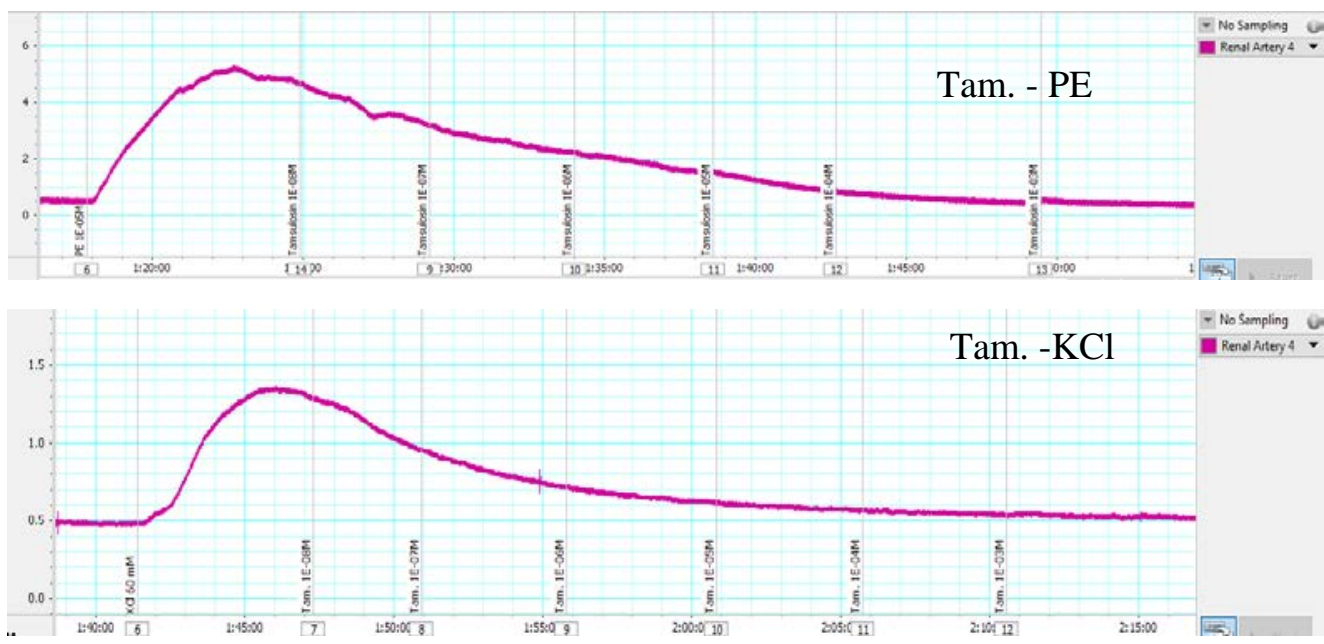

Trace Chart 1a and 1b. Typical chart view trace shows the dose-dependent vasorelaxant effect of Tam. on renal artery pre contracted with $\mathrm{PE}\left(1 \times 10^{-5} \mathrm{M}\right)$ and $\mathrm{KCl}(60 \mathrm{mM})$. The $\mathrm{X}$-axis illustrates the time in minutes and $\mathrm{Y}$-axis of each channel represent developed tension in grams. Spotted lines indicate the addition of Tam. (M) in a cumulative manner. 